\title{
Investigation of Patients with Spontaneous Rupture of the Urinary Bladder
}

\author{
Yoshihiro Inoue, Yasuhisa Fujino, Makoto Onodera, Satoshi Kikuchi, Masayuki Sato, \\ Hisaho Sato, Masahiro Kojika, Yasushi Suzuki, Gaku Takahashi, Shigehiro Shibata \\ Department of Critical Care Medicine, School of Medicine, Iwate Medical University, Morioka, Japan \\ Email: yinoue@iwate-med.ac.jp
}

Received 28 November 2015; accepted 15 December 2015; published 18 December 2015

Copyright @ 2015 by authors and Scientific Research Publishing Inc.

This work is licensed under the Creative Commons Attribution International License (CC BY). http://creativecommons.org/licenses/by/4.0/

(c) (i) Open Access

\begin{abstract}
Non-traumatic rupture of the urinary bladder is termed "spontaneous rupture of the urinary bladder". Although this disorder is relatively rare, when the bladder ruptures into the abdominal cavity, urine leaking into the abdominal cavity leads to the development of urinary peritonitis. We encountered seven patients with spontaneous rupture of the urinary bladder at our institution between 1987 and 2012. Six of these patients were women, all of whom had undergone surgery and radiotherapy to treat malignant uterine tumor. All seven patients suddenly developed abdominal pain and ascites. Urea nitrogen (UN) and creatinine (Cre) levels were greater in ascites than in the blood in all patients. Although all patients were treated conservatively, recurrence was identified in three patients. Recurrence was observed in only one of the four patients who received hyperbaric oxygen therapy. Conclusion: Hyperbaric oxygen therapy may be effective for recurrence of spontaneous rupture of the urinary bladder.
\end{abstract}

\section{Keywords}

Spontaneous Rupture of the Urinary Bladder, Hyperbaric Oxygen Therapy (HBO)

\section{Introduction}

Urinary bladder rupture can be traumatic or non-traumatic. Non-traumatic urinary bladder rupture is referred to as "spontaneous rupture of the urinary bladder". When the bladder ruptures, urine leaks into the abdominal cavity, leading to urinary peritonitis. Because patients develop exacerbating abdominal pain at this point, emergency transport is often necessary. In some cases, patients present signs of peritoneal irritation and large amounts of ascitic fluid at initial examination, and subsequently undergo emergency surgery on suspicion of acute peritonitis or gastrointestinal perforation.

How to cite this paper: Inoue, Y., Fujino, Y., Onodera, M., Kikuchi, S., Sato, M., Sato, H., Kojika, M., Suzuki, Y., Takahashi, G. and Shibata, S. (2015) Investigation of Patients with Spontaneous Rupture of the Urinary Bladder. Open Journal of Clinical Diagnostics, 5, 141-144. http://dx.doi.org/10.4236/ojcd.2015.54023 
Spontaneous rupture of the urinary bladder is considered relatively rare, but is attracting attention as a long-term complication of radiation cystitis that develops after radiotherapy for malignant tumors of the female reproductive system. We report herein a summary of patients with spontaneous rupture of urinary bladder treated at our institution.

\section{Subjects}

We investigated seven patients (6 women, 1 man) with spontaneous rupture of the urinary bladder we encountered at our institution between 1987 and 2012. Patients ranged in age between 55 and 79 years old. We obtained from the patients to publish these cases.

\section{Results}

The initial symptom in all seven patients was sudden onset of abdominal pain. Medical history of the patients included malignant uterine tumor $(n=5)$ and bladder tumor $(n=1)$. These six patients had all been receiving radiotherapy. The male patient had been under long-term hospitalization at a psychiatric facility for schizophrenia and neurogenic bladder (Table 1). All patients exhibited massive ascites on abdominal computed tomography (CT) or ultrasound examination and underwent paracentesis (ascites tapping). Urea nitrogen (UN) and creatinine (Cre) levels were greater in the aspirated ascitic fluid than in the blood for all patients (Table 2). Cystography was performed in six patients, and leakage of the contrast agent into the abdominal cavity was observed in three.

Table 1. Characteristics of the cases (1).

\begin{tabular}{|c|c|c|c|c|c|c|c|}
\hline & Case 1 & Case 2 & Case 3 & Case 4 & Case 5 & Case 6 & Case 7 \\
\hline Age & 55 & 65 & 55 & 79 & 59 & 71 & 66 \\
\hline Gender & Female & Female & Male & Female & Female & Female & Female \\
\hline Past history & $\begin{array}{c}\text { Cancer of } \\
\text { urinary bladder }\end{array}$ & $\begin{array}{c}\text { Cancer of } \\
\text { uterine cervix }\end{array}$ & $\begin{array}{l}\text { Schizophrenia } \\
\text { and neurogenic } \\
\text { bladder }\end{array}$ & $\begin{array}{l}\text { Cancer of } \\
\text { uterine body }\end{array}$ & $\begin{array}{c}\text { Cancer of } \\
\text { uterine cervix }\end{array}$ & $\begin{array}{c}\text { Cancer of } \\
\text { uterine cervix }\end{array}$ & $\begin{array}{c}\text { Cancer of } \\
\text { uterine cervix }\end{array}$ \\
\hline $\begin{array}{c}\text { Passage of } \\
\text { radiation } \\
\text { Therapy } \\
\text { (years) }\end{array}$ & 16 & 18 & $(-)$ & 40 & 15 & 22 & 22 \\
\hline $\begin{array}{c}\text { Chief } \\
\text { complaint }\end{array}$ & Abdominal pain & Abdominal pain & Abdominal pain & Abdominal pain & Abdominal pain & Abdominal pain & Abdominal pain \\
\hline $\begin{array}{c}\text { Leak of } \\
\text { cystography }\end{array}$ & $(-)$ & $(+)$ & $(+)$ & $(-)$ & $(-)$ & Not performed & $(+)$ \\
\hline $\begin{array}{c}\text { The number } \\
\text { of HBO }\end{array}$ & $(-)$ & $(-)$ & $(-)$ & 20 & 20 & 8 & 20 \\
\hline Recurrence & $(+)$ & $(+)$ & $(-)$ & $(-)$ & $(-)$ & $(-)$ & $(+)$ \\
\hline Outcome & $\begin{array}{c}\text { Death from } \\
\text { other } \\
\text { disease } \\
25 \text { years later }\end{array}$ & $\begin{array}{l}\text { Survival for } \\
21 \text { years }\end{array}$ & $\begin{array}{l}\text { Survival for } \\
15 \text { years }\end{array}$ & $\begin{array}{l}\text { Survival for } \\
10 \text { years }\end{array}$ & $\begin{array}{l}\text { Desth from } \\
\text { primary } \\
\text { disease } 7 \\
\text { years later }\end{array}$ & $\begin{array}{c}\text { Survival for } \\
9 \text { years }\end{array}$ & $\begin{array}{l}\text { Survival for } \\
3 \text { years }\end{array}$ \\
\hline
\end{tabular}

Table 2. UN and creatinine in serum and ascites.

\begin{tabular}{|c|c|c|c|c|}
\hline & Serum UN (mg/dl) & Creatinine (mg/dl) & Ascites UN (mg/dl) & Creatinine (mg/dl) \\
\hline Case 1 & 19.5 & 0.8 & 72 & 9.7 \\
\hline Case 2 & 48.1 & 5.4 & 71 & 11.6 \\
\hline Case 3 & 50.8 & 6.8 & 87 & 24.8 \\
\hline Case 4 & 22.3 & 2.1 & 60 & 12.4 \\
\hline Case 5 & 22.1 & 2.1 & 40 & 7.9 \\
\hline Case 6 & 18.6 & 0.7 & 81 & 8.1 \\
\hline Case 7 & 20.8 & 1 & 39 & 6.1 \\
\hline
\end{tabular}

UN: urea nitrogen; normal range of UN in serum: 9.0 - $20.0 \mathrm{mg} / \mathrm{dl}$; normal range of creatinine in serum: $0.4-1.1 \mathrm{mg} / \mathrm{dl}$. 
None of the patients underwent surgery, but recurrence was observed in one of the four patients who underwent hyperbaric oxygen therapy (HBO), and in two of the three who did not receive HBO. Although two patients died, rupture was not the direct cause of death (Table 1 ).

\section{Discussion}

Spontaneous rupture of the urinary bladder refers to non-traumatic rupture of the urinary bladder. This condition is considered relatively rare, and is associated with signs of peritoneal irritation when rupture occurs into the abdominal cavity and also with massive ascites on diagnostic imaging. Emergency surgery may thus be indicated based on suspicion of acute abdomen or gastrointestinal perforation of unknown cause [1]-[3]. However, if spontaneous rupture of the urinary bladder can be suspected and diagnosed, acute-phase surgery can be avoided in favor of antibiotic therapy and catheterization of the urinary bladder.

Spontaneous rupture of the urinary bladder often occurs in conjunction with radiation cystitis caused by radiotherapy performed after surgery to treat a diseased urinary bladder, especially corpus uteri carcinoma or cervical cancer [4]-[6]. This is attributed to the following mechanism: during surgical operations in the pelvic cavity, a so-called neurogenic bladder-induced urination impairment is present and radiation is exposed with the bladder wall in a stretched state, leading to progression of irreversible modifications triggered by radiation injury such as loss of bladder epithelium and blood flow disorder, thereby causing the bladder wall to gradually weaken and ultimately rupture [7]. The interval from radiation exposure to rupture varies greatly, but reportedly ranges between 3 - 40 years [4] [6]. Time periods in our cases were all within this range.

For diagnosis, spontaneous rupture of the urinary bladder is often initially considered based on the clinical course since onset and a history of uterine surgery or radiotherapy. While this disorder is easily suspected if the physician has previously encountered such a case, use of the above history as a clue is essential, because the disorder itself is relatively rare. Since a large amount of ascites is often observed in this disorder, UN and Cre levels in ascitic fluid aspirate can be measured. In all our cases UN and creatinine levels in ascetic fluid were greater than in serum. If these levels are greater in the aspirate than in serum measured at the same time, urine leakage into the abdominal cavity can be diagnosed. Definitive diagnosis can be made if leakage of contrast agent outside the bladder is observed on cystography. However, only 3 patients from the present study exhibited contrast leakage, indicating that the absence of leakage does not eliminate the possibility of urinary bladder rupture.

When urine that has leaked into the abdominal cavity is re-absorbed by the peritoneum, serum concentrations of UN and Cre increase. This can lead to the diagnosis of acute renal failure and a bias towards performing emergency surgery on misdiagnosis of exacerbated acute abdomen. Caution is therefore necessary. Elevations of these factors are also known to improve promptly with appropriate conservative treatment [1].

If the condition can be diagnosed as spontaneous rupture of urinary bladder at an outpatient clinic, an indwelling urinary catheter can be inserted and antibiotic treatment initiated, leading to rapid improvements in signs of peritoneal irritation and ascites. Emergency surgery can thus be avoided. An indwelling urinary catheter is also effective for preventing recurrence, and an increase in the frequency of conservative treatment is anticipated [4].

HBO (2.5 atm, 84 min, 8 - 20 sessions) has been attracting attention as a method for treating spontaneous rupture of the urinary bladder. HBO is known to combat radiation cystitis by acting on areas that became impaired due to hypoxia-ischemia caused by necrotic capillaritis or obstructive endarteriolitis, by promoting granular tissue formation mediated through angiogenesis and fibroblast proliferation, thereby enhancing properties such as leukocidal actions and promoting recovery. HBO has therefore also been reported as effective in preventing recurrence of spontaneous bladder rupture [8] [9]. In our cases recurrence was observed in only one of the four patients who underwent $\mathrm{HBO}$.

\section{Conclusion}

We treated seven patients with spontaneous rupture of the urinary bladder. Most patients developed this condition after radiotherapy in conjunction with surgery for cervical cancer or corpus uteri carcinoma. All patients were diagnosed on an outpatient basis and showed improvements with insertion of an indwelling urinary catheter and antibiotic therapy. However, the condition still recurred in three patients. Recurrence was observed in only one of the four patients who underwent HBO. HBO may be effective for recurrence of spontaneous rupture of the urinary bladder. 


\section{Conflict of Interests}

Authors declare no conflict of interests for this article.

\section{References}

[1] Moriwaki, Y., Yamamoto, T., Suzuki, N. and Sugiyama, M. (2008) A Case of Spontaneous Rupture of the Urinary Bladder Diagnosed Digestive Tract Perforation with Abdominal Free Air. Japanese Journal of Diagnosis and Therapy, 96, 1621-1624.

[2] Nakashima, M., Hirao, Y., Kimura, Y., Hayashi, K., Yokomizo, H. and Hirata, T. (2009) A Case of Spontaneous Rupture of the Urinary Bladder with Intra-Abdominal Free Air. Journal of Japan Surgical Association, 70, 1199-1203. http://dx.doi.org/10.3919/jjsa.70.1199

[3] Kawai, Y., Kitaoka, H., Seki, T., Urizono, Y., Hata, M. and Okuchi, K. (2013) A Case of Spontaneous Urinary Bladder Rupture Accompanied by Intraperitoneal Free Air. Journal of Japan Surgical Association, 74, 1081-1085. http://dx.doi.org/10.3919/jisa.74.1081

[4] Igami, T., Yamaguchi, A., Isogai, M., Hori, A., Kaneoka, Y., Takahashi, Y., Ri, M., Suzumura, K., Sugawara, G., Akagawa, T., Ogawa, K. and Mori, T. (1999) Four Cases of Spontaneous Rupture of the Associated with Radiation Cystitis. Journal of Japan Surgical Association, 60, 2453-2457. http://dx.doi.org/10.3919/jisa.60.2453

[5] Takemura, H., Baba, K., Yajima, M., Yamakawa, K., Nishida, S. and Iwamoto, T. (2000) A Case of Recurrent Spontaneous Vesical Rupture Subsequent to Irradiation for Uterine Cancer. Acta Urologica Japonica, 46, 269-271.

[6] Murata, Y., Goshima, H., Kato, H. and Tanemura, A. (2007) Two Cases of Rapture of the Urinary Bladder Due to Radiation Cystitis. Journal of Japan Surgical Association, 68, 2604-2609.

[7] Kawamoto, K., Noguchi, S., Sakuramoto, T., Shyuin, T., Noguchi, K., Kinoshita, Y., Kubota, Y. and Hosaka, M. (1992) Clinical Analysis of 46 Cases of Radiation Cystitis. Acta Urologica Japonica, 38, 395-398.

[8] Ogata, M., Kudo, S., Kashiwabara, Y., Nozawa, T., Matsushita, Y., Tanji, S., Koike, H. and Fujioka, T. (2001) Hyperbaric Oxygen Is Beneficial for the Prevention of Recurrent Spontaneous Intraperitoneal Rupture of the Bladder. Japanese Journal of Urological Surgery, 14, 53-56.

[9] Terada, N., Matsui, Y., Ohara, H., Ichioka, K., Yoshimura, K. and Terai, A. (2003) Hyperbaric Oxgen Therapy for Spontaneous Rupture of the Bladder Subsequent to Irradiation: A Report of Two Cases. Nishinihon Journal of Urology, 65, 558-561. 